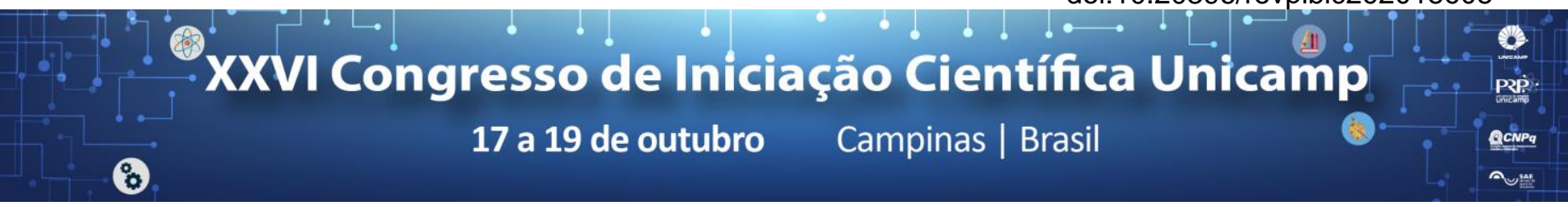

\title{
INVESTIGATING THE POSSIBILITIES OF OCARINA CRAFTING IN MUSIC EDUCATION
}

\author{
Igor A. Aguilar* (igor.abdo.aguilar@gmail.com), Profa. Dra. Adriana N. A. Mendes \\ Instituto de Artes/ Unicamp
}

\begin{abstract}
This research features the history, characteristics and particularities of the musical instrument ocarina and proposes to stipulate models of ocarinas that can be crafted in classrooms by children with the teacher's guidance. The study is based on authors Coleman (1927), Ramos (2011) and Matsunobu (2013). At the end of the research, we chose three models of ocarinas, as well as three types of clay and three types of tools that can be used for crafting this instrument in a classroom. Furthermore, we point to the possibility of students crafting their own instruments with quality superior to musical toys.
\end{abstract}

\section{Key words:}

Instrument-crafting, Ocarina, Music Education

\section{Introduction}

This study intended to:

1. Investigate the standard models of ocarinas

2. Compare and pick models of ocarinas that demonstrate potential use in music education through crafting instruments

3. Present possible types of clay that are accessible financially and malleable enough to make ocarinas in a classroom

4. List tools for the crafting of the ocarinas that are safe and accessible for use by students while still being effective to make well-tuned instruments

\section{Method}

\section{Results and Discussion}

First, we conducted a bibliographic research both about instrument building as one approach to music education and also about the history of the ocarina.

Then, we compared fingering, range and methods of making of the models found and we chose a few to test crafting methods at the Ceramic Laboratory of the Art Institute of UNICAMP.

Finally, we have selected the tools that are safe to be used, accessible to students and also have potential of crafting well-tuned ocarinas.

\section{Discussion}

Often, in music education there is the issue about having enough instruments available for a classroom of fair quality at an accessible price. One way to approach this is with instrument making. Commonly, when dealing with instrument crafting in a music education context, most educators tend to make simple instruments that lead to a single presentation in which the created instruments unfortunately are later discarded for not being considered as "real instruments". Other concern is the need to work with older students, due to the type of tools and space necessary to build well-tuned instruments (Matsunobu, 2013). Further issue is the ethnic approach to music history appreciation in general music classes (Coleman, 1927), which tends to have an European centered point of view.

We have found three types of tools that can be potentially implemented for molding and tuning the clay made ocarinas: (1) traditional wooden tools, (2) plastic cake baking tools and (3) metal telescoping tubes.

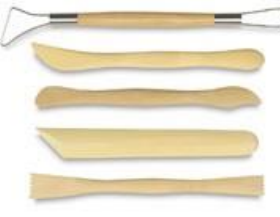

Image 1. Wooden <https://bit.ly/2Jg4vRO>

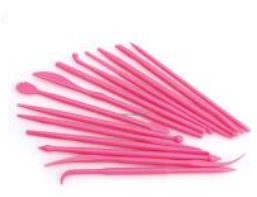

Image 2. Plastic <https://bit.ly/2zwlGyJ>

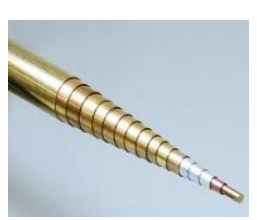

Image 3. Tube
We researched fourteen methods and types of ocarinas and chose three types: (4) The Italian Transverse, (5) The English Pendant and (6) The Inline. To make these three types of ocarinas we can use simple methods of crafting, with traditional techniques of pottery.

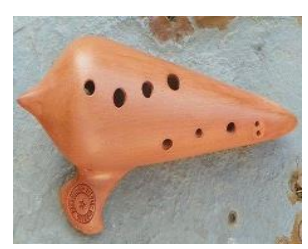

Image 4. Italian <https://bit.ly/2L27a2C>

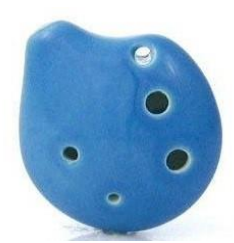

mage 5. E. Pendant <https://bit.ly/2kw6szp>



Image 6. In Line <https://bit.ly/2JedLtG>

\section{Conclusions}

The chosen models of ocarinas and types of materials have high potential in being valuable approaches for music education through instrument making. The research points to the need of crafting these models.

\section{Acknowledgement}

We would like to thank CNPq and UNICAMP for supporting this project. And also to register special thanks to Giorggio Pacchioni and Chris Heuer for helping the researcher to develop the skill of crafting ocarinas.

COLEMAN, S. N. Creative experience through making musical instruments. Progressive Education, v. 4, n. 1, p. 18-23, 1927.

MATSUNOBU, Koji. Instrument-making as music-making: An ethnographic study of shakuhachi students' learning experiences. International Journal Of Music Education. [s.1], p. 190-201. 17 jun. 2013. Available at: <https://doi.org/10.1177\%2F0255761413486858>. Acessed : 17 Mar. 2018.

RAMOS, David Docjazz. The Ocarina Guide. Texas, Usa: Docjazz4, 2011. Available at: <Ocarinaguide.com>. Acessed : 20 Oct. 2017. 